\title{
PARAMETRIC STUDY ON THE LATERAL TORSIONAL BUCKLING OF STAINLESS STEEL I BEAMS WITH CLASS 4 CROSS-SECTIONS IN CASE OF FIRE
}

\author{
Nuno Lopes, Pedro Gamelas, Paulo Vila Real \\ RISCO, Department of Civil Engineering, University of Aveiro, Aveiro, Portugal
}

\begin{abstract}
For predicting the behaviour of beams with thin-walled I sections, named Class 4 in Eurocode 3 (EC3), it is necessary to account for the occurrence of both local and lateral torsional buckling (LTB). These instability phenomena, which are intensified at elevated temperatures, should be accurately considered in design rules. The fire design guidelines for stainless steel members, given in Part 1-2 of EC3, propose the use of the same formulae developed for carbon steel (CS) elements. However, these two materials have different constitutive laws, leading to believe that the use of those formulae should be validated. This work presents a parametric numerical study on the behaviour of stainless steel beams with Class 4 I sections at elevated temperatures. The influences of several parameters such as stainless steel grade, loading type and cross section slenderness are evaluated, and comparisons between the obtained numerical results and EC3 rules are presented.
\end{abstract}

Keywords: stainless steel, class 4 sections, beams, Eurocode 3.

\section{INTRODUCTION}

Even though the initial cost, stainless steel has several desirable characteristics for a structural material. And its smaller need for thermal protection material can be one additional factor for improving stainless steel competitiveness in construction.

The most common stainless steel grades in structural applications are of the groups austenitic, ferritic or austenitic-ferritic (duplex) (Euro-Inox et al., 2006, CEN, 2005a, CEN, 2006a). One grade from each group was considered in this research work.

The existence of simplified design rules for the evaluation of the fire resistance of structures is very important as designers do not always have access to applications dealing with advanced calculation methods. The fire part of EC3 (CEN, 2005a) provides design rules for stainless steel structural elements at elevated temperatures, which adopt the design formulae developed for CS (conventional steel) members. However, in this same standard, the constitutive laws in case of fire for stainless steel differ from the ones of CS. This fact leads to believe that different design rules should be given for stainless steel members.

The design LTB curve proposed in EC3 for the fire resistance of Class 4 beams is based on the research work developed by Vila Real et al. $(2001,2003)$ for the case of simply supported Class 1 and 2 (stocky profiles (CEN, 2005b)) I- and H-shaped beams with fork supports and uniform bending diagrams. This curve was after improved to take into account the influence of the pattern of the bending moments diagram (Vila Real et al., 2007). Recent studies on the fire resistance of structural elements with CS Class 4 sections have been made in the scope of the European research project FIDESC4 (Zhao et al., 2015). One of the outcomes of this project was a new design proposal for Class 4 beams in case of fire (Couto, 2015). In addition, a recent study (Lopes et al., 2014) on Class 4 stainless steel beams under fire situation has shown the need for future developments on the their design formulae.

The main objective of this work is to present a parametric numerical study, using the software SAFIR (Franssen, 2005), on the behaviour of stainless steel beams with Class 4 I sections at elevated temperatures. The influences of several parameters such as stainless steel grade, loading type and cross section slenderness are evaluated. The program CAST3M (Le Fichoux, 1998) was 
used for the purpose of obtaining the local and global instability modes of the studied beams, which were used to define the geometrical imperfections introduced on the finite element models and to obtain the critical bending moment needed for the LTB slenderness calculation. Finally, the obtained numerical results are compared against the buckling curves from the design rules included in EC3 and proposal developed for CS Class 4 beams.

\section{SIMPLIFIED FIRE DESIGN APPROACHES}

\subsection{EC3 proposed formulae}

Clause 1.1.2 (9) from Part 1-2 of EC3 refers that the same design formulation prescribed for CS elements subjected to elevated temperatures must be used for stainless steel members. According to the this standard, the LTB resistance moment for Class 4 cross-sections, is

$$
M_{b, f i, t, R d}=\chi_{L T, f_{i}} W_{e f f, y} k_{0.2 p, \theta} f_{y} \frac{1}{\gamma_{M, f i}}
$$

$W_{\text {eff }, y}$ is the effective section modulus of the cross-section (CEN, 2006a) and $\chi_{L T, f i}$ is given by

$$
\chi_{L T, f i}=\frac{1}{\phi_{L T, \theta}+\sqrt{\left(\phi_{L T, \theta}\right)^{2}-\left(\bar{\lambda}_{L T, \theta}\right)^{2}}} \text { with } \phi_{L T, \theta}=\frac{1}{2}\left[1+\alpha \bar{\lambda}_{L T, \theta}+\left(\bar{\lambda}_{L T, \theta}\right)^{2}\right]
$$

In this expression the imperfection factor $\alpha$ depends on the steel grade and is determined with

$$
\alpha=0.65 \sqrt{235 / f_{y}}
$$

\subsection{Proposed design curve for Class 4 carbon steel beams (Couto, 2015; Zhao et al., 2015)}

Based on the parametric study performed in the scope of the research project FIDESC4 (Couto, 2015; Zhao et al., 2015), new design curves were proposed. The proposed expressions are based on the actual design curve of Part 1-2 of Eurocode 3, but considering

$$
\phi_{L T, \theta}=0.5\left[1+\alpha_{L T, \text { new }}\left(\bar{\lambda}_{L T, \theta}-\bar{\lambda}_{L T, 0}\right)+\bar{\lambda}_{L T, \theta}^{2}\right]
$$

being the values of $\alpha_{L T}$ and $\bar{\lambda}_{L T, 0}$ given in Table 1 . Three different curves are given (L1, L2 and L3) depending on the effective section factor. $\bar{\lambda}_{L T, 0}$ corresponds to the introduction of a plateau.

Table 1 - Design curve of beams with slender cross-sections.

\begin{tabular}{|cccc|}
\hline Curve & Limits & $\alpha_{L T, \text { new }}$ & $\bar{\lambda}_{L T, 0}$ \\
\hline L1 & $\frac{W_{e f f, y}}{W_{e l, y}}>0.9$ & $1.25 \varepsilon=1.25 \sqrt{235 / f_{y}}$ & 0.2 \\
\hline L2 & $0.8<\frac{W_{e f f, y}}{W_{e l, y}} \leq 0.9$ & $1.00 \varepsilon=1.00 \sqrt{235 / f_{y}}$ & 0.2 \\
\hline L3 & $\frac{W_{e f f, y}}{W_{e l, y}} \leq 0.8$ & $0.75 \varepsilon=0.75 \sqrt{235 / f_{y}}$ & 0.2 \\
\hline
\end{tabular}

Additionally, Studies by Vila Real et al., 2007 proposed that the design LTB resistance moment should be determined, in case of fire, with the modified reduction factor

$$
\chi_{L T, f i \text { mod }}=\frac{\chi_{L T, f i}}{f} \text { but } \quad \chi_{L T, f i, \bmod } \leq 1
$$

To consider the influence of the bending diagrams, the factor $f$ is determined with 


$$
f=1-0.5\left(1-k_{c}\right), \text { for beams with end moments } k_{c}=0.6+0.3 \psi+0.15 \psi^{2} \text { but } k_{c} \leq 1
$$

In this proposal for Class 4 CS sections the value of $f$ is limited to a minimum of 0.8 (Couto, 2015).

\section{NUMERICAL MODELLING}

\subsection{Cases studied}

Simply supported welded I beams with fork supports and were analysed. The stainless steel grades considered in this study were the austenitic 1.4301, the ferritic 1.4003 and the austenitic-ferritic 1.4462 (CEN, 2005a, 2006). All studied sections are of Class 4, however, different classes of the internal elements were analysed. Table 2 presents the analysed sections ("Height of the web" $\mathrm{x}$ "Web thickness" + "Section width" x "flange thickness". The numerical tests were made with uniform temperatures in the cross section. The temperatures chosen were $350{ }^{\circ} \mathrm{C}, 500{ }^{\circ} \mathrm{C}, 600^{\circ} \mathrm{C}$ and $700{ }^{\circ} \mathrm{C}$ deemed to be representative of the typical critical temperatures in steel structural elements.

Table 2 - Chosen sections

\begin{tabular}{lcccccc}
\hline \multirow{2}{*}{ Section } & \multicolumn{7}{c}{1.4301} & \multicolumn{2}{c}{1.4003} & \multicolumn{2}{c}{1.4462} \\
& web & flange & web & flange & web & flange \\
\hline $500 \times 5+255 \times 8$ & C4 & C4 & C4 & C4 & C4 & C4 \\
$400 \times 5+200 \times 8$ & C4 & C4 & C4 & C4 & C4 & C4 \\
$320 \times 5+200 \times 8$ & C3 & C4 & C4 & C4 & C4 & C4 \\
$350 \times 5+150 \times 8$ & C4 & C3 & C4 & C4 & C4 & C4 \\
$250 \times 5+200 \times 8$ & C2 & C4 & C3 & C4 & C4 & C4 \\
$400 \times 5+135 \times 8$ & C4 & C2 & C4 & C3 & C4 & C4 \\
$220 \times 5+200 \times 8$ & - & - & - & - & C3 & C4 \\
$350 \times 5+100 \times 8$ & - & - & - & - & C4 & C3 \\
$230 \times 5+200 \times 8$ & - & - & C2 & C4 & - & - \\
$170 \times 5+200 \times 8$ & - & - & - & - & C2 & C4 \\
$400 \times 5+120 \times 8$ & - & - & C4 & C2 & - & - \\
$400 \times 5+91 \times 8$ & - & - & - & - & C4 & C2 \\
\hline
\end{tabular}

The beams with the sections presented in Table 2 were subjected to uniform bending diagram. However, beams with the section $500 \times 5+255 \times 8$ were also analysed with triangular bending moments $(\psi=0)$ and bi-triangular bending moments $(\psi=-1)$.

\subsection{FEM model description}

A three-dimensional FEM-model was developed to perform geometrically and materially nonlinear numerical analyses including imperfections (GMNIA). As local buckling phenomena were likely to occur, shell finite elements were used. The material model recommended in Part 1-2 of EC3 was used for the stainless steel behaviour at elevated temperatures.

According to Part 1-5 of EC3 (CEN, 2006b), the shape of the local and global (LTB) instability modes obtained with software CAST3M (Le Fichoux, 1998), applying the interface RUBY (Couto et al., 2013), were used to define the geometrical imperfections. The maximum value for the imperfections was made equal to $80 \%$ of the essential manufacturing tolerances given in EN 1090-2 (CEN, 2008) (L/750 for the global imperfections and b/100 for the local imperfections). 

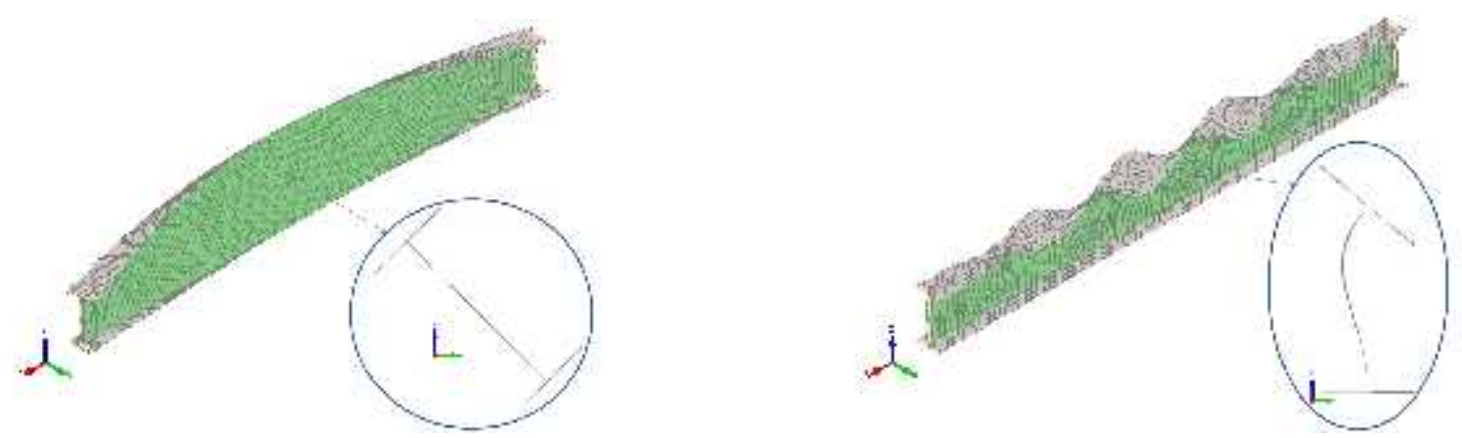

Fig. 1 Imperfection shapes (corresponding respectively to the global and local buckling modes).

The adopted residual stresses follow the typical patterns for CS welded sections (Chen, 1991; Ashraf, 2006), considered constant across the thickness of the web and flanges.

\section{PARAMETRIC STUDY}

In order to compare the numerical results with the design prescriptions, for the determination of the cross-section resistances, numerical analyses were also performed using the same tested beams, but laterally restrained. This numerical cross-section resistance was used to determine the reduction factor of the tested beams bearing capacity. In addition, the LTB critical bending moments were also obtained numerically for all beams models, with the software CAST3M, using the interface RUBY. These numerical critical moments together with the numerical cross section resistances were applied on the calculation of the LTB relative slenderness values.

\subsection{Section slenderness}

In this section, comparisons between the numerical resistances and the tested buckling curves, for beams with sections composed of internal elements of different classifications and different effective section factors, are presented (see Fig. 2). The proposal for Class 4 CS beams (section 2.2 of this paper and "Class 4 proposal CS" in the graph) provides a better approximation to the obtained results for low LTB slenderness values, by the introduction of the plateau in the curve. However, for high LTB slenderness values, EC3 is always better than "Class 4 proposal CS", being this later too much on the safe side for high effective section factors. The results lead to believe that different limits and imperfection factors should be developed.
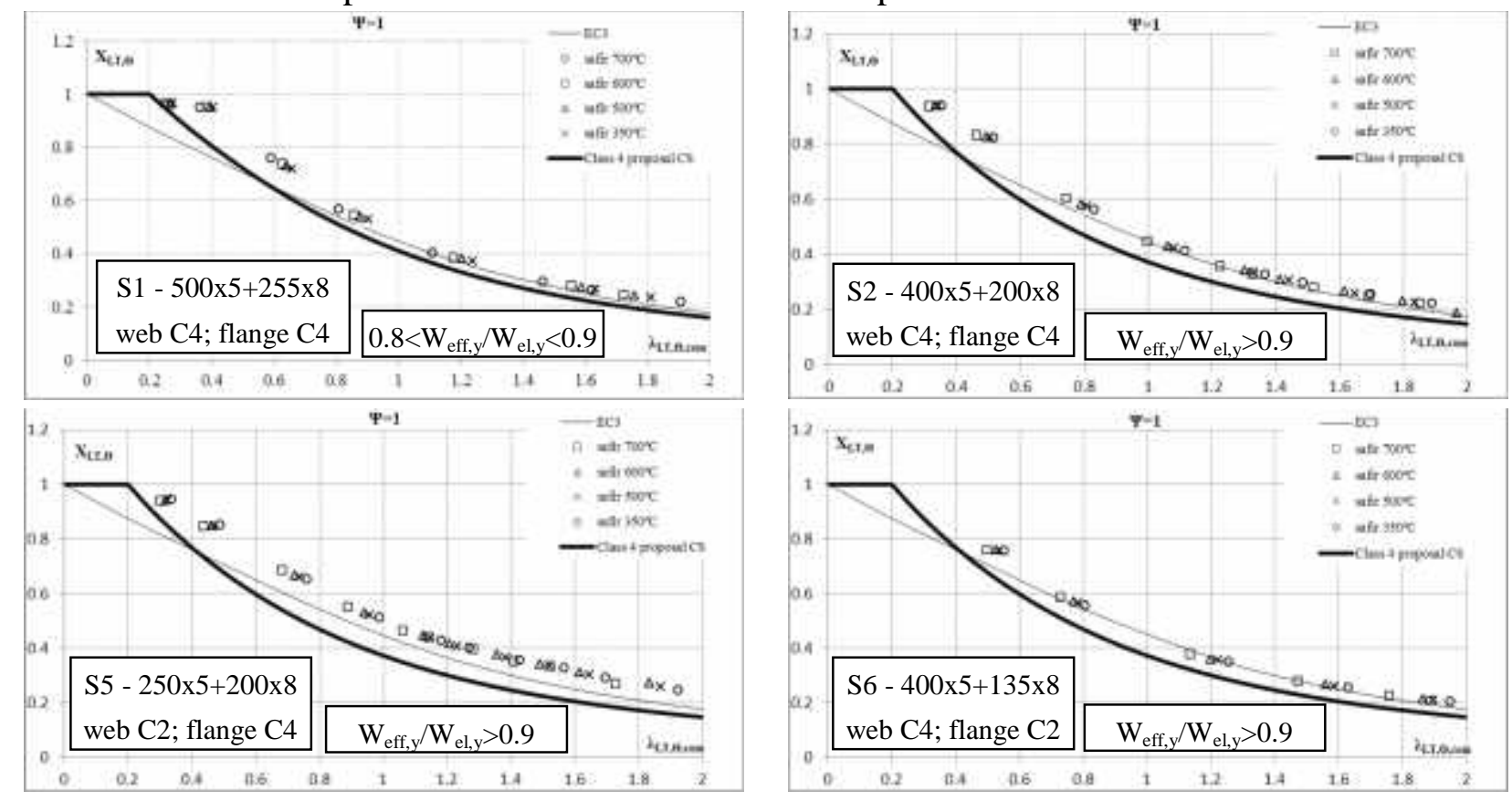

Fig. 2 Comparisons between numerical results and design expressions for beams with different crosssections of the grade 1.4301 with uniform bending diagram. 


\subsection{Loading type}

Regarding the loading type, the $f$ factor considered in the proposal for Class 4 CS beams introduces a big improvement in the approximation to the numerical results. Fig. 3 shows the obtained comparisons for beams with the section $500 \times 5+255 \times 8$ of the grade 1.4301 , considering triangular and bi-triangular bending diagrams (respectively $\psi=0$ and $\psi=-1$ ). It should be noticed that the results obtained for $\psi=-1$ with low LTB slenderness are affected by shear buckling phenomenon, which is not in the scope of this work, therefore, they were not considered.
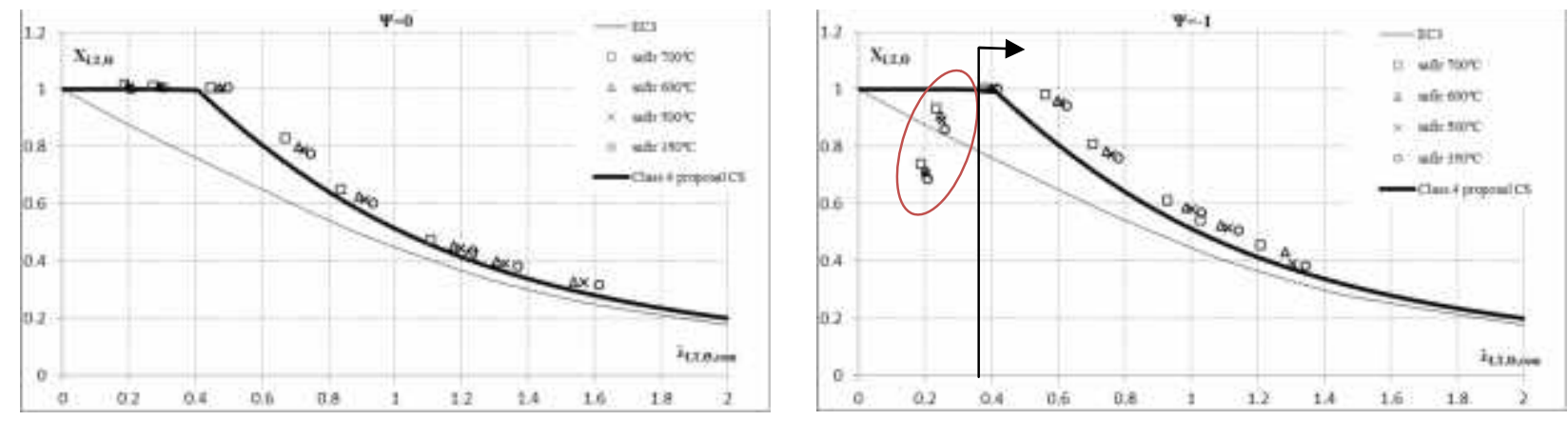

Fig. 3 Comparisons between numerical results and design expressions for beams with different bending diagrams with the section $\mathrm{S} 1-500 \times 5+255 \times 8$ of the grade 1.4301 .

\subsection{Stainless steel grade}

Fig. 4 presents all the obtained results, here it is clear that the results have a wider dispersion for the grades 1.4003 and 1.4462, which indicates that they should be separately analysed. Both design procedures are too conservative.
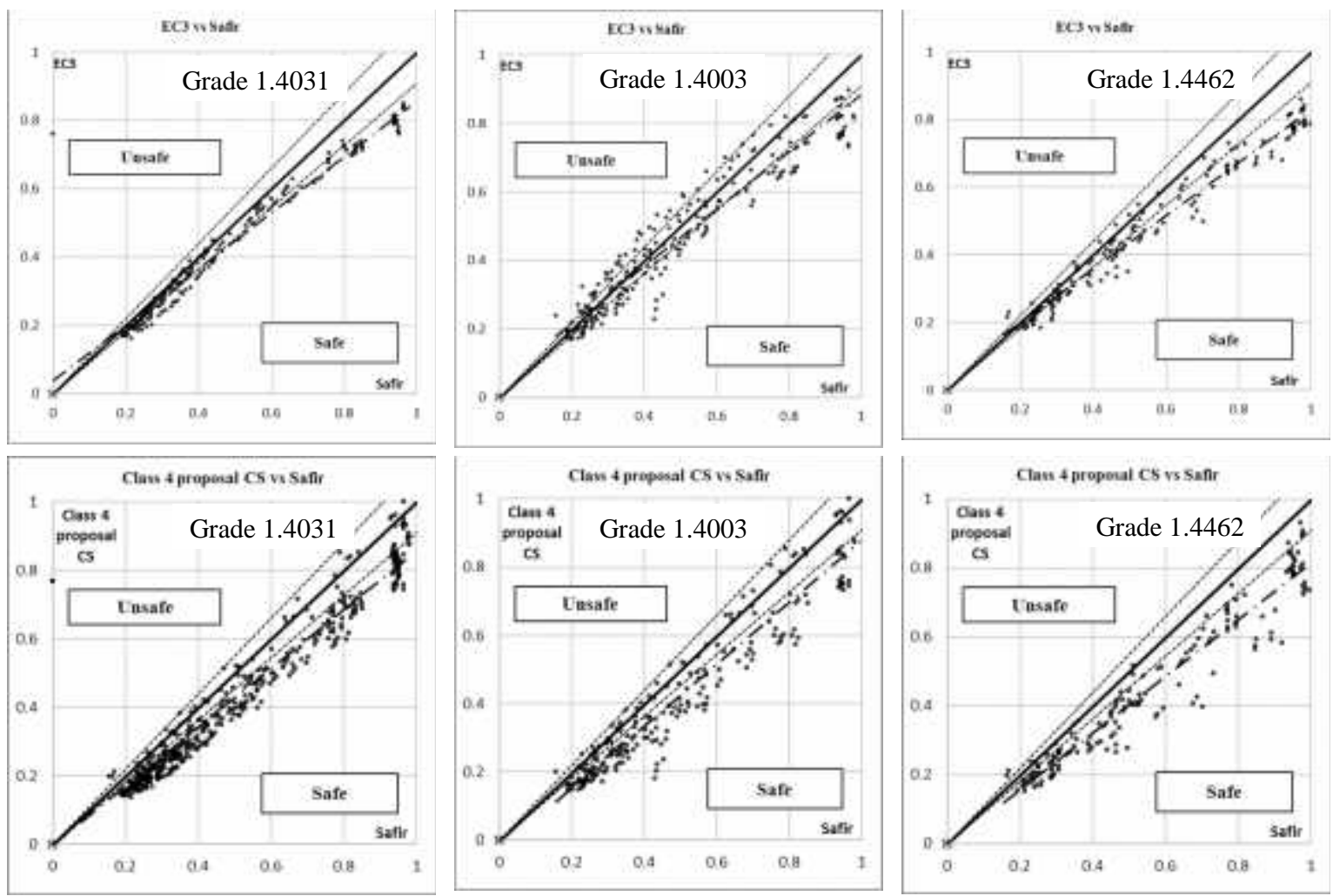

Fig. 4 Comparison between all the results and the design proposals for each stainless steel grade. 


\section{CONCLUSIONS}

A parametric study on the fire resistance of stainless steel I beams with Class 4 cross sections was presented. The influences of the cross section slenderness, loading type and stainless steel grade on the determination of the ultimate bending capacity of those beams in case of fire were analysed.

It was concluded that the consideration of the cross section slenderness in stainless steel beams should be different from CS beams. The loading type is relevant and it should be considered, the procedure presented for that purpose seems to be adequate. Finally, the accuracy of the results differs in function of the stainless steel grade, which leads to conclude that the consideration of the yield strength at normal temperature, on the imperfection factor for the LTB curves, is not enough to differentiate the stainless steel grade.

In addition, both the design approach in EC3 and proposal for CS Class 4 beams are too conservative. The introduction of a plateau improves the approximation to the numerical results for small slenderness and it should be considered in the design buckling curves of Class 4 stainless steel I beams. As it was expected it can be concluded that the same formulation should not be used for both CS and stainless steel thin walled beams in case of fire.

\section{REFERENCES}

Ashraf A., Gardner L., Nethercot D., 2006. Finite element modelling of structural stainless steel cross-sections, Thin-Walled Structures 44/10, 1048-1062.

CEN, 2005a. EN 1993-1-2 Eurocode 3: Design of Steel Structures - Part 1-2: General rules Structural fire design, Brussels, Belgium.

CEN, 2005b. EN 1993-1-1, Eurocode 3, Design of Steel Structures - Part 1-1: General rules and rules for buildings, Brussels, Belgium.

CEN, 2006a. EN 1993-1-4 Eurocode 3, Design of Steel Structures - Part 1-4: General rules Supplementary Rules for Stainless Steels, Brussels, Belgium.

CEN, 2006b. EN 1993-1-5, Eurocode 3: Design of Steel Structures - Part 1-5: Plated structural elements, Brussels, Belgium.

CEN, 2008. EN 1090-2, Execution of Steel and aluminium Structures - Part 2: Technical Requirements for the execution of steel structures, Brussels, Belgium.

Chen W.F., Lui E.M., 1991. Stability design of steel frames, CRC Press, 1991.

Couto C, Vila Real P., Lopes N., 2013. RUBY an interface software for running a buckling analysis of SAFIR models using Cast3M, Universidade Aveiro

Couto C., 2015. Fire design of uniform and tapered class 4 steel members, PhD thesis in Civil Engineering at the University of Aveiro.

Euro Inox, Steel Construction Institute, 2006. Design Manual for Structural Stainless Steel, 3rd edition.

Franssen J.-M. 2005. SAFIR A Thermal/Structural Program Modelling Structures under Fire, Engineering Journal 42/3, 143-158.

Le Fichoux E., 1998. "Présentation et utilisation de CASTEM 2000”. ENSTA-LME.

Lopes N., Vila Real P., 2014. Class 4 stainless steel I beams subjected to fire, Thin Walled Structures, ISSN: 0263-8231, Elsevier, volume 83, pp. 137-146.

Vila Real P., Franssen J.-M., 2001. Numerical Modelling of Lateral Buckling of Steel I Beams Under Fire Conditions - Comparison with Eurocode 3, J. Fire Protection Eng. 11/2, 112-128.

Vila Real P., Piloto P., Franssen J.-M., 2003. A New Proposal of a Simple Model for the LateralTorsional Buckling of Unrestrained Steel I-Beams in Case of Fire: Experimental and Numerical Validation, Journal of Constructional Steel Research 59/2, 179-199.

Vila Real P., Lopes N., Silva L., Franssen J.-M., 2007. Parametric Analysis of the LateralTorsional Buckling Resistance of Steel Beams in Case of Fire, Fire Safety J., 42/6-7, 416-424.

Zhao B., Franssen J.-M., Morente F., Vila Real P., Wald F., Sanzel A., 2015. Fire Design of Steel Members with Welded or Hot-rolled Class 4 Cross-sections, report of the FIDESC4 project 